\title{
ALGUMAS AFINIDADES: ALEXANDRE DUMAS, CAMILO CASTELO BRANCO E MACHADO DE ASSIS
}

\section{PAULO MOTTA OLIVEIRA}

Universidade de São Paulo

São Paulo, São Paulo, Brasil

Resumo: Este artigo pretende analisar a representação do narrador em obras de Alexandre Dumas, Camilo Castelo Branco e Machado de Assis.

Palavras chave: Alexandre Dumas; Camilo Castelo Branco; Machado de Assis; romance.

\section{SOME AFFINITIES: ALEXANDRE DUMAS, CAMILO CASTELO BRANCO AND MACHADO DE ASSIS}

Abstract: This article intends to analyze the representation of the narrator in works by three authors: Alexandre Dumas, Camilo Castelo Branco and Machado de Assis.

Keywords: Alexandre Dumas; Camilo Castelo Branco; Machado de Assis; novel.

crítica literária portuguesa habitualmente aproxima a obra de
Camilo Castelo Branco da de Balzac. Alguns parcos exemplos, a que
poderíamos acrescentar outros: Alberto Pimentel e Teófilo Braga, no

${ }^{1}$ Cf. BRAGA, As modernas ideias da literatura portuguesa; PIMENTEL, O romance do romancista; CASTRO, Contribuição para o estudo da influência de Balzac em Portugal e no Brasil.

${ }^{2}$ Quando está a se referir à falta de dinheiro de Simão, o narrador escreve: "Deviam de ocorrer-lhe ideias aflitivas, que os romancistas raras vezes atribuem aos seus heróis. Nos romances todas as crises se explicam, menos a crise ignóbil da falta de dinheiro. Entendem os novelistas que a matéria é baixa e plebeia. [...]. Balzac fala muito em dinheiro; mas dinheiro a milhões: não conheço, nos cinquenta livros que tenho dele, um galã num entreato da sua tragédia a cismar no modo de arranjar uma quantia. CASTELO BRANCO, Obras completas, v. III, p. 448.

D.0.I: 10.1590/1983-682120158152

Este texto está licenciado sob uma Licença Creative Commons do tipo atribuição BY.

Machado de Assis Linha, São Paulo, v. 8, n. 15, p. 10-25, junho 2015

Universidade de São Paulo - Faculdade de Filosofia, Letras e Ciências Humanas 
segunda edição de Eusébio Macário, em que afirma: "há vinte e cinco anos [...] Balzac tinha em mim o mais inábil e ordinário dos seus discípulos". 3

Considero que esta comparação, da forma como geralmente é feita, é um equívoco, pois acaba por considerar como falta aquilo que afasta a narrativa camiliana da balzaquiana. Teófilo Braga, por exemplo, aponta como um dos grandes defeitos de Camilo o de não ter articulado a sua obra em torno de uma ideia central, como fez o criador da Comédia humana. A unidade da obra camiliana, creio, é dada por outras estratégias. Um autor que percebeu bem um aspecto central desta unidade foi Teixeira de Pascoaes. Em $O$ penitente - biografia que escreveu sobre o autor de Anátema - afirmou: "Onde ela [a tua cara, Camilo] se destaca é em quase toda a tua obra. Como Dostoiévski, não pertences à classe dos grandes escritores invisíveis, Balzac e Victor Hugo, por exemplo".4

É justamente esta não invisibilidade que aqui me interessa, pois ela permite vincular a produção camiliana com a de um outro escritor, raramente com ele comparado: Alexandre Dumas. De início é interessante apontar que Dumas ocupa, na crítica literária francesa, um espaço semelhante ao que Camilo ocupou durante todo o século XX, inferior ao dos grandes escritores do período, como Balzac, na França, e Eça de Queirós, em Portugal. Apesar do enorme sucesso que Dumas teve enquanto vivo e do fato de continuar, até hoje, a ser republicado, ele precisou esperar o seu bicentenário para que, finalmente, os seus restos mortais fossem para o Panteão, ao lado de outros que chegaram bem mais rápido, como Victor Hugo, que lá foi enterrado quando morreu.

A proximidade entre Dumas e Camilo pode ser reforçada se levarmos em consideração que este foi o romancista português mais profícuo nos anos 50 e 60 - período em que publicou 43 romances, enquanto aquele foi o autor mais traduzido no período, com o inacreditável total de 157 traduções. ${ }^{5}$ Eram, portanto, escritores populares, que escreviam tentando viver de sua pena, e que faziam muito sucesso em Portugal.

Mas creio que a mais interessante proximidade entre os dois autores está no fato de Dumas também ser, em parte de sua produção, um escritor não invisível. Certamente, se lermos apenas as suas grandes obras, como $O$ conde de Monte Cristo ou Os três mosqueteiros, não veremos essa semelhança. Ela ocorre em uma série de outros livros, hoje quase totalmente esquecidos. Se

\footnotetext{
${ }^{3}$ Idem, p. 463-4.

${ }^{4}$ PASCOAES, O penitente, p. 30.

${ }^{5}$ Cf. CABRAL, Dicionário de Camilo Castelo Branco, p. 82-83; RODRIGUES, A tradução em Portugal, 2. v. $-1835 / 1850$; 3. v. $-1851 / 1870$.
} 
confrontarmos, por exemplo, Pauline, Os irmãos corsos ou Gabriel Lambert com os romances de Camilo, encontraremos no escritor francês alguns dos procedimentos que estão presentes nos romances camilianos: um narrador que se apresenta como o próprio autor e que muitas vezes escuta uma história que outro lhe conta; a reprodução de documentos - como cartas e diários - que comprovariam a veracidade da história contada; a pluralidade de vozes narrativas; a relação entre livros autobiográficos e obras ficcionais, que se comunicam como se possuíssem o mesmo estatuto. Essas características, presentes na produção camiliana, parecem assim advir de um aproveitamento de estratégias já utilizadas por Dumas. Se não tenho como aprofundar aqui essa comparação, cito apenas o exemplo de Gabriel Lambert, livro de 1843, e que teve sua primeira tradução em Portugal cinco anos depois.

Veraneando em 1835 em Toulon, o narrador - que se assume como Alexandre Dumas - encontra um forçado, Gabriel Lambert, que lhe parece familiar, mas que ele não consegue lembrar em que momento havia, antes, conhecido. Quando, mais tarde, o forçado lhe envia um bilhete informando o nome que assumira na sociedade parisiense - o de visconde Henri de Faverne -, o narrador se recorda de quem ele é, e conta ao leitor o que dele se lembrava. Após retornar a Paris, encontra-se com um médico, o doutor Fabien, que cuidou do visconde após um duelo, e que anotou em um caderno todos os encontros que teve com Henri, anotações que o narrador reproduz no romance, e entre as quais encontramos a reprodução de várias cartas e mesmo de um longo depoimento de Marie Granger, uma namorada de Henri que fora por ele abandonada. Por fim o narrador reproduzirá uma carta de um outro forçado, Rossignol, através da qual teremos acesso aos últimos lances da história de Gabriel Lambert, sem se esquecer de, para atestar a veracidade da missiva, explicitamente indicar que a copia com os erros de ortografia que lá existiam.

Como podemos notar, aqui encontramos vários procedimentos usuais nas narrativas camilianas. O livro de Dumas é composto por um narrador principal - que se confunde com o próprio autor - e que cede a narrativa a vários outros, reproduzindo, em sua obra, documentos que foram escritos por esses narradores secundários ou por outros personagens.

Creio que esses aspectos apontados são suficientes para comprovar a hipótese, que poderia ser reforçada por uma leitura mais desenvolvida deste e das duas outras obras que indiquei. Se não me parece produtiva a aproximação entre Balzac e Camilo com o objetivo de ver neste um discípulo 
ou um continuador do romance balzaquiano em Portugal, ${ }^{6}$ a aproximação com Dumas, autor que em Portugal possuía o mesmo estatuto que o romancista de Seide, mostra-se muito mais pertinente. Julgo que algumas das posturas narrativas assumidas por Camilo nas décadas de 50 e 60 já haviam sido utilizadas por Dumas nas décadas de 30 e 40.

Penso, ainda, que essa aproximação é produtiva por vários motivos. $\mathrm{O}$ primeiro, de caráter mais geral, é indicar que, para melhor conhecermos a produção camiliana, é necessário visitar certos romances de Alexandre Dumas que são, hoje, totalmente esquecidos. Não se trata - façamos uma comparação que por seu contraste poderá mostrar melhor o que quero dizer - de recuperar romances pouco trabalhados de Flaubert ou mesmo de Victor Hugo, mas de um escritor considerado popular, já em seu tempo atacado por ter criado uma fábrica de produzir folhetins, até hoje constantemente revisitado pelos mais diferentes meios da cultura de massa - cinema, televisão e quadrinhos, por exemplo - e normalmente menosprezado pela crítica literária - o que pode ser comprovado pelo parco número de críticos, mesmo na França, que trabalham de forma sistemática com a sua obra. Ou seja, neste caso específico é necessário romper com certo preconceito - que ainda existe - com a obra de Dumas, o que pode significar, se quisermos ampliar o que aqui notamos, que talvez apenas conhecendo melhor uma série de escritores que fizeram muito sucesso em Portugal na primeira metade do século XIX é que poderemos melhor entender a literatura então produzida pelos autores portugueses, e não só a de Camilo.

Em relação ao próprio Camilo, julgo essa aproximação extremamente profícua, pois pode nos levar a ver na sua obra não o que falta, mas o que sobeja. Camilo não se apropria dos procedimentos de Dumas para copiá-los, agradando assim a um público habituado a ler o autor do Conde de Monte Cristo. Ele vai além. Cito apenas um exemplo. Em Amor de salvação o narrador se apresenta como um cronista. Afirma que teria tomado conhecimento dos fatos narrados graças a um encontro, em dezembro de 1863, com o protagonista da história, Afonso de Teive. O narrador o havia conhecido anteriormente, mas assim que o vê não o reconhece, como ocorre na cena inicial de Gabriel Lambert. Também no livro de Camilo há não só a transcrição de cartas dos personagens, como também a presença de várias referências que permitem ao leitor concluir que o narrador do livro é o

\footnotetext{
${ }^{6}$ Devo salientar que Aníbal Pinto de Castro aponta que Camilo não é um continuador ou discípulo de Balzac. Porém, ao compará-los - aspecto que não tenho como aqui desenvolver - considera Camilo como inferior ao autor francês, em parte porque o meio que este frequenta é inferior ao de Paris.
} 
próprio autor.

Se essas semelhanças, às quais poderíamos somar outras, mostram que Camilo está aqui se apropriando de certa forma narrativa presente na produção dumasiana dos anos 30, os efeitos que tira dessa forma vão muito além daqueles presentes no autor francês.

Nos três livros de Dumas a que me referi, essa estratégia serve principalmente para reforçar a verossimilhança da obra, fazendo com que o leitor acredite estar diante de um depoimento verdadeiro. No livro de Camilo, o narrador assume a postura de um editor que coordena os vários materiais de que se utiliza, como as referidas cartas, as memórias que tinha de Afonso de Teive antes de seu reencontro com ele e a reprodução aparentemente textual da conversa que manteve com este personagem. Mas esse material é utilizado não apenas para reforçar a veracidade do livro, mas principalmente para criar na obra uma espécie de duplo discurso, que desestabiliza a fala de seu principal informante. $O$ que Afonso conta ao narrador, e esse reproduz para seus leitores, é uma versão do passado, motivada pelo seu presente. Ele fora apaixonado por Teodora, mas quem o salva é a sua prima Mafalda, cuidadosa cigarra que foi adquirindo todos os bens que ele vendeu por causa de sua amante. A sua versão é tão falsa ou verdadeira como pode ser qualquer versão. Todo discurso é motivado pelos interesses de quem o profere. É o que o narrador, desestabilizando o discurso que reproduz, parece querer indicar.

Certamente a forma como Camilo se apropria do legado de Dumas é fundamental para o seu procedimento, recorrente, de fazer digressões e conversar com o leitor. Ao criar, entre a história que narra e o leitor que a lê, este ente fantasmático que é - o chamemos assim - o Camilo ficcional, ele faz com que todos os comentários pareçam advir deste. É o fictício autor que conosco fala, aceitando ou desestabilizando o que lhe é dito por seus informantes.

É a partir desta característica que, creio, podemos ligar a narrativa camiliana com a machadiana, criando uma espécie de nova genealogia.

Como apontou Paulo Franchetti:

A leitura dos quatro primeiros romances de Machado mostra um desenho interessante, no que diz respeito à assunção da voz autoral e da representação do leitor. Em Ressurreição, 1872, há 3 momentos importantes nos quais o autor assume a voz autoral e dialoga diretamente com o leitor.

[...] Já no livro seguinte, A mão e a luva, 1874, são inúmeras as vezes nas 
quais o autor assume a voz autoral e interpela ou dialoga com o leitor. [...] Em Helena, 1876, as referências ao leitor são mínimas, sem especificidade nem digressão. E a voz autoral não se apresenta. Por fim, em Iaiá Garcia, 1878, a narração transcorre totalmente neutra, sem assunção da voz e sem tematização do leitor ou do processo de escrita.

Como se vê, o narrador machadiano evolui numa direção entre 1872 e 1874, mas muda de rumo entre 1876 e 1878 . Apaga-se a figura autoral, a tematização do livro e do ato da escrita desaparecem, o narrador não se apresenta nem interage com o leitor. O ápice desse processo é Iaiá Garcia. Dir-se-ia que Machado caminhava numa direção precisa: abandonava o modelo da narração romântica, de narrador intrusivo, e adotava o narrador onisciente neutro. Ou seja, caminhava na direção do tempo, no que diz respeito à constituição do narrador realista.

No entanto, após 1878, o rumo se alterou, como sabemos. ${ }^{7}$

Mas, devemos notar, esta mudança de rumo, se pensarmos nos próprios termos apontados por Paulo Franchetti, não é homogênea. No primeiro romance da nova fase, Memórias póstumas de Brás Cubas, temos uma espécie de autobiografia de seu protagonista e pretenso autor. Dez anos mais tarde, vamos encontrar em Quincas Borba uma narrativa em terceira pessoa, em que há um narrador que faz comentários e que em algumas raras vezes, cerca de dez, interpela o leitor. Em 1899 novamente encontramos uma postura parecida com a do primeiro romance, e Bentinho faz a sua autobiografia em Dom Casmurro. Em 1904 temos um procedimento novo - narrado em terceira pessoa, o livro foi escrito pelo conselheiro Aires, que também aparece como personagem da narrativa. Por fim, no último romance de Machado, Memorial de Aires, de 1908, temos uma narrativa híbrida, como é afirmado na introdução:

Tratando-se agora de imprimir o Memorial, achou-se que a parte relativa a uns dois anos (1888-1889), se for decotada de algumas circunstâncias, anedotas, descrições e reflexões, - pode dar uma narração seguida, que talvez interesse, apesar da forma de diário que tem. Não houve pachorra de a redigir à maneira daquela outra, - nem pachorra, nem habilidade. Vai como estava, mas desbastada e estreita, conservando só o que liga o mesmo assunto. O resto aparecerá um dia, se aparecer algum dia.

M. de A. ${ }^{8}$

${ }^{7}$ FRANCHETTI, Machado e Camilo. Acesso em 11 mar. 2015.

${ }^{8}$ ASSIS, Obra completa, v. 1, p. 1027. 
Assim, é um livro escrito por Aires, mas editado por esse Machado ficcional, aspecto a que mais à frente voltaremos.

Como podemos notar, destes romances apenas um - Quincas Borba não apresenta um autor que se coloca entre o livro e a história contada, mesmo que escutemos, em alguns momentos, a voz do narrador, como ocorre nos capítulos CXII-CXIV. Nos outros quatro é sempre através do ponto de vista do narrador/autor que temos acesso aos acontecimentos.

Ora, os romances de Camilo - normalmente escritos em terceira pessoa, mas em que ele usualmente aparece como narrador/autor - já haviam mostrado como é parcial este tipo de narrativa. Ao nos referirmos a Amor de salvação, pudemos indicar como o narrador mostra ser incorreto o ponto de vista de seu informante e apresenta, sem explicitar, a sua perspectiva sobre a história. É possível citar pelos menos um exemplo ainda mais significativo, quando o autor dá elementos para que o seu próprio discurso seja desacreditado, encenando que a sua própria versão dos fatos também é parcial, e fruto de sua perspectiva e de seus interesses: A queda de um anjo.

Em dois momentos do livro o narrador se apresenta como Camilo. No primeiro afirma que

[...] pernoitando [Calisto] em não sei que solar de damas dadas à leitura amena, pediu algum livro, e deram-lhe um romance meu. Consta-me que deixou o volume com as margens anotadas de galicismos e manchas de toda a casta. Imaginem quantas punhaladas eu dei naquele lusitaníssimo coração! ${ }^{9}$

Em outro trecho escreve que o protagonista, relendo antigos papéis seus com os quais não mais concordava, "ordenou a um criado que queimasse o manuscrito. O criado não o queimou. Escondeu-o sem mau intento; e alguma vez saberá o mundo literário como aqueles papéis vieram à minha mão". ${ }^{10}$

Ora, nesta narrativa se conta a história de um morgado muito tradicionalista que, após ser eleito deputado e mudar-se para Lisboa, acaba por se modificar de forma radical, e termina o livro vivendo adulterinamente com Ifigênia, enquanto sua esposa traída também acaba cedendo ao seu interesseiro primo Lopo, e com ele passa a viver.

Toda a narrativa é montada para que acreditemos no recíproco amor

${ }^{9}$ CASTELO BRANCO, cit., v. V, p. 884.

${ }^{10}$ Idem, p. 1003. 
entre Calisto e Ifigênia, o que romanticamente justificaria a relação não sacramentada. Mas o leitor atento poderá perceber que há uma outra possibilidade de leitura.

Quando Calisto recebe um cartão de Ifigênia, antes de conhecê-la, mas já a sabendo bela e viúva, prepara para o primeiro encontro de ambos a sua saleta, mudando toda a mobília e transformando-a "em recinto digno de uma Ponce de Leão", ${ }^{11}$ sobrenome da personagem.

Em outro momento, quando já eram amantes e frequentavam o teatro, ele viu num camarote à frente Adelaide, por quem fora apaixonado e que o havia desprezado e ridicularizado: "Numa dessas noites, estava na frisa fronteira à de Calisto a família Sarmento. Adelaide não despregava o óculo de Ifigénia [...]. Calisto exultava de delícias incomparáveis. Era a vingança, a carapinhada dos deuses num meio-dia de julho, a vingança de amador menoscabado". ${ }^{12}$

Podemos perceber de que é feito o amor de Calisto, tão insistentemente afirmado pelo narrador. Já em relação ao amor de Ifigênia, a que o narrador dedica o título de um capítulo - "E ela amava-o!" -, devemos notar que existe uma enorme distância entre a feliz amante de Calisto do fim do livro e a viúva que pela primeira vez se apresentou a seu primo. Esta havia proferido frases como "envolvi meu coração na mortalha de meu marido, no túmulo dele o fechei", e "[abjurei a todas as alegrias do coração] que não condigam com a minha situação de viúva". ${ }^{13}$ Assim, a última Ifigênia teve de transigir com esses valores morais para atingir a felicidade. Se essa distância já seria um indício das características não explicitadas dessa personagem, um trecho, no final do penúltimo capítulo do livro, poderá levar o leitor a perceber muito mais do que vem escrito: "O barão esperava que a mulher morresse, para legitimar os seus meninos [...]. A baronesa, que, digamo-lo depressa, não rejeitou o título do marido, esperava que o marido se aniquilasse na perdição dos seus costumes, para também legitimar o seu Barnabé [...]".14

Ora, o amor entre Teodora e Lopo, seu primo, era o amor entre um anjo que também caiu - a esposa de Calisto -, e que pretendia, em certo sentido, se vingar de seu marido, e um primo interesseiro que, sem dinheiro, seduziua para poder viver graças à fortuna dela. ${ }^{15} \mathrm{Na}$ equivalência final entre as

${ }^{11}$ Idem, p. 944.

${ }^{12}$ Idem, p. 987.

${ }^{13}$ Idem, p. 952.

${ }^{14}$ Idem, p. 1004.

${ }^{15}$ É paradigmática do caráter de Lopo a cena, no final do capítulo XXIX, em que ele convence Teodora de que sempre a amou, e de que todos os desatinos que cometeu ocorreram por causa desse amor. Cf. CASTELO BRANCO, cit., v. V, p. 973-977. 
situações de Calisto e Teodora, não é difícil perceber que as situações dos dois casais são simétricas: também entre Calisto e Ifigênia temos um amor entre primos, um rico e o outro pobre, e um desejo de vingança. Sem nada ser explicitamente dito, ficamos a pensar se, por trás da pele de uma cândida Ifigênia, não existiria também um lobo que precisa, para sobreviver, do dinheiro de seu primo. Os dois primos pobres da trama terminam, curiosamente, como amantes dos primos ricos, constituindo com esses uniões que, se não são sacramentadas, são muito próximas de um casamento.

Mas o narrador - para aqueles que conheciam a versão da vida de Camilo que ele ia narrando em seus livros, ou que era divulgada pela imprensa - vai além no descrédito de seu próprio discurso. Uma série de elementos mostra uma grande proximidade entre Calisto Elói e Camilo: ambos vivem um amor não sacramentado, com Ifigênia e Ana Plácido; o ano da queda do morgado da Agra de Freimes, 1859, é o mesmo em que Ana abandonou o seu marido para viver com Camilo; no presente da narrativa, 1864, ambos os casais possuem dois filhos ilegítimos.

Ou seja, o narrador teria motivos para esconder o interesse que perpassa a relação Calisto-Ifigênia, pois o mesmo interesse poderia perpassar a relação Camilo-Ana. O discurso seria fruto dos seus interesses pessoais, e o desmascaramento possível seria não só da situação de Calisto, mas da de Camilo. Uma forma ainda mais contundente de mostrar que qualquer discurso é motivado, qualquer verdade, relativa.

Vendo o livro sob este prisma, certamente pode-se pensar em um trecho de Roberto Schwarz sobre Memórias póstumas:

Ao colocar na posição de sujeito narrativo o tipo social de Brás Cubas o verdadeiro alvo da sátira - Machado tomava um rumo perverso e desnorteante. Camuflada pela primeira pessoa do singular, que a ninguém ocorreria usar em prejuízo próprio e com propósito infamante, a imitação ferina dos comportamentos da elite criava um quadro de alta mistificação: cabe ao leitor descobrir que não está diante de um exemplo de autoexame e requintada franqueza, mas de uma denúncia devastadora. ${ }^{16}$

Também no livro de Camilo encontramos um narrador que se apresenta como autor, usando a primeira pessoa do singular em prejuízo próprio e com propósito infamante. O seu discurso é apresentado como pessoalmente motivado, e a narrativa conta uma versão dos fatos, conveniente para o

${ }^{16}$ SCHWARZ, Um mestre na periferia do capitalismo: Machado de Assis, p. 177-178. 
narrador/autor, ao mesmo tempo em que, subterraneamente, desacredita a sua própria imagem de adúltero perdoável pela paixão, destruindo, assim, uma certa aura de condescendência que cercava o escritor.

Apesar das semelhanças, há um aspecto que distancia esse livro dos quatro romances de Machado indicados. Nestas obras a simulação do narrador-autor desloca-se do autor real, para encarnar em personagens específicos. Aqui não encontramos Machado se apresentando como o autor de seus livros - como encontrávamos Dumas e Camilo - mas Brás Cubas, Bentinho e Aires. Postura que, devemos assinalar, Camilo já havia utilizado de forma explícita em um de seus livros: refiro-me, é lógico, a Coração, cabeça e estômago. Talvez por isso esta seja a obra do autor de Anátema que mais ecoa na produção machadiana da dita segunda fase. Se não tenho como aqui fazer o trabalho detalhado de confronto que seria necessário, vou me ater a apenas alguns exemplos significativos, sem poder sobre eles me aprofundar.

Certamente o primeiro aspecto que chama a atenção é o fato de Silvestre da Silva ser um autor defunto, como o seriam, anos mais tarde, não só Brás Cubas mas também, geralmente o esquecemos, o conselheiro Aires.

Há ainda a semelhança, já apontada pela crítica, entre a "ideia grandiosa e útil" do "emplasto anti-hipocondríaco, destinado a aliviar a nossa melancólica humanidade", ${ }^{17}$ ideia fixa que acabou por matar Brás Cubas, e o elixir divulgado em um jornal por Silvestre da Silva, que não pretendia curar a hipocondria, "esta enfermidade, de origem corpórea" conhecida pela medicina, mas sim a "melancolia [que] [...] tanto ataca os inteligentes como os idiotas". ${ }^{18}$

Podemos, ainda, encontrar uma postura narrativa semelhante entre Brás Cubas, que afirma ser a "diferença radical entre [seu] livro e o Pentateuco" o fato de que "Moisés, que também contou a sua morte, não a pôs no introito, mas no cabo", ${ }^{19}$ e Silvestre, que assim se refere às suas memórias:

Nestas minhas confissões hei-de ser modesto, e verdadeiro, como Santo Agostinho e J.-J. Rousseau; mas, ainda assim mais honesto que o santo e que o filósofo. O pejo e a natural vaidade querem pôr-me mordaça; mas eu hei-de expiar as minhas parvoíces, confessando-as. Se, por miséria minha, me baralhei e confundi com tantos e tão graúdos tolos, farei

\footnotetext{
${ }^{17}$ ASSIS, cit., p. 416.

18 CASTELO BRANCO, cit., v. III, p. 836. Já, em outro momento, refleti sobre esta aproximação OLIVEIRA, Camilo Castelo Branco: de personas e emplastos -, que também foi analisada por Marta de Senna - SENNA, O silêncio do bruxo: Machado de Assis e Camilo Castelo Branco.

${ }^{19}$ ASSIS, cit., p. 415.
} 
agora minha distinção pondo, em letra redonda, que o era. Não me consta que algum dos meus amigos fizesse outro tanto. ${ }^{20}$

Também aqui podemos lembrar a análise de Schwarz:

Assim, desde a abertura o romance apresenta um narrador-personagem que dispõe do todo da tradição ocidental com espetacular desenvoltura. A sua superioridade consiste em não se dar jamais por achado, a olhos alheios ou aos próprios, e se afirma através da desidentificação sistemática de si mesmo, cuja contrapartida é a constante adoção de novos papéis, logo postos de lado por sua vez. Ao longo deste movimento são deixadas umas pelas outras, tendencialmente, todas as ideias e formas à disposição de um homem culto do tempo, que ficam relativizadas (e também estereotipadas e barateadas). ${ }^{21}$

Além do uso - de forma barateada - dos legados de Santo Agostinho e Jean-Jacques Rousseau, o trecho do crítico poderia ser um bom resumo do próprio movimento que segue o protagonista de Coração, cabeça e estômago, que vai mudando de posturas como mudaria de roupa, e não tem pudor de ridicularizar o tolo que foi.

Poderíamos indicar outros exemplos que apontariam semelhanças entre estas obras, mas prefiro, para fechar este artigo, mostrar os fantasmas de Silvestre e de seu editor em outras paragens.

Comecemos pelo Humanitismo de Quincas Borba, e pela forma como ele explica a Rubião por que não teme morrer.

Não há morte. $\mathrm{O}$ encontro de duas expansões, ou a expansão de duas formas, pode determinar a supressão de uma delas; mas, rigorosamente, não há morte, há vida, porque a supressão de uma é a condição da sobrevivência da outra, e a destruição não atinge o princípio universal e comum. ${ }^{22}$

Podemos aqui encontrar certos ecos da irônica filosofia apresentada pelo editor de Coração, cabeça e estômago, quando ele conversa com o futuro cunhado de Machado, Faustino Xavier de Novaes:

- O meu amigo Faustino Xavier de Novaes conheceu perfeitamente

${ }^{20}$ CASTELO BRANCO, cit., v. III, p. 753.

${ }^{21}$ SCHWARZ, cit., p. 23.

22 ASSIS, cit., p. 560. 
aquele nosso amigo Silvestre da Silva...

- Ora, se conheci!... Como está ele?

- Está bem: está enterrado há seis meses.

- Morreu?!

- Não morreu, meu caro Novaes. Um filósofo não deve aceitar no seu vocabulário a palavra morte, senão convencionalmente. Não há morte. $\mathrm{O}$ que há é metamorfose, transformação, mudança de feitio. [...] O nosso amigo Silvestre da Silva, a esta hora, anda repartido em partículas. Aqui faz parte da garganta dum rouxinol; além, é pétala duma tulipa; acolá, está consubstanciado num olho de alface; pode ser até que eu o esteja bebendo neste copo de água que tenho à minha beira e que tu o encontres nos sertões da América, alguma vez, transfigurado em cobra cascavel, disposto a comer-te, meu Faustino. ${ }^{23}$

Os trechos postos em confronto mostram que o Humanitismo talvez descenda não só do darwinismo e do positivismo, mas também desta filosofia para a qual um átomo de Silvestre poderá transfigurar-se numa perigosa cascavel, como por sinal já apontou Marta de Senna. ${ }^{24}$ Em ambas a mesma crença na inexistência da morte, em ambos a mesma práxis quase socrática de tentar convencer, em um diálogo, o seu interlocutor. E a ironia que, fatalmente, produziria um sorriso no leitor.

Um último exemplo, com que fechamos nosso raciocínio. Comecemos pela advertência de Esaú e Jacó:

Quando o conselheiro Aires faleceu, acharam-se-lhe na secretária sete cadernos manuscritos, rijamente encapados em papelão. Cada um dos primeiros seis tinha o seu número de ordem, por algarismos romanos, I, II, III, IV, V, VI, escritos a tinta encarnada. O sétimo trazia este título: Último.

A razão desta designação especial não se compreendeu então nem depois. Sim, era o último dos sete cadernos, com a particularidade de ser o mais grosso, mas não fazia parte do Memorial, diário de lembranças que o conselheiro escrevia desde muitos anos e era a matéria dos seis. Não trazia a mesma ordem de datas, com indicação da hora e do minuto, como usava neles. Era uma narrativa; e, posto figure aqui o próprio Aires, com o seu nome e título de conselho, e, por alusão, algumas aventuras, nem assim deixava de ser a narrativa estranha à matéria dos seis cadernos. Último por quê?

${ }^{23}$ CASTELO BRANCO, cit., v. III, p. 729-730.

${ }^{24}$ SENNA, cit., p. 128-129. 
A hipótese de que o desejo do finado fosse imprimir este caderno em seguida aos outros, não é natural, salvo se queria obrigar à leitura dos seis, em que tratava de si, antes que lhe conhecessem esta outra história, escrita com um pensamento interior e único, através das páginas diversas. Nesse caso, era a vaidade do homem que falava, mas a vaidade não fazia parte dos seus defeitos. Quando fizesse, valia a pena satisfazêla? Ele não representou papel eminente neste mundo; percorreu a carreira diplomática, e aposentou-se. Nos lazeres do ofício, escreveu o Memorial, que, aparado das páginas mortas ou escuras, apenas daria (e talvez dê) para matar o tempo da barca de Petrópolis.

Tal foi a razão de se publicar somente a narrativa. ${ }^{25}$

Lembremos, ainda, do trecho de Memorial de Aires que atrás citamos, em que o ficcional editor Machado afirma que teve de retirar do manuscrito "algumas circunstâncias, anedotas, descrições e reflexões" para transformá-lo numa "narração seguida".

Vejamos o que diz o editor Camilo Castelo Branco dos papéis que herdou do finado Silvestre:

Vamos à papelada, como dizem os outros.

Tenho debaixo dos olhos, mal enxutos da saudade, três volumes escritos da mão de Silvestre. O primeiro, na lauda, que serve de capa, tem a seguinte inscrição em letras maiúsculas: "CORAÇÃO".

O segundo, menos volumoso, diz: "CABEÇA".

O título do terceiro, e maior volume, é: "ESTÔMAGO".

Nenhum deles designa época; mas quem tiver, como eu, particular conhecimento do indivíduo, pode, sem grande erro cronológico, datar os três manuscritos. [...]

Silvestre, como sabes, tinha muita lição de maus livros. [...]

Os manuscritos de Silvestre careciam de ser adulterados para merecerem a qualificação de romance. E coisa que eu não faria, se pudesse. Acho aqui em páginas correntemente numeradas sucessos sem ligação nem contingência. Umas histórias em princípio, outras que começam pelo fim e outras que não têm fim nem princípio. Pode ser que eu, alguma vez, em notas, elucide as escuridades do texto, ou ajunte às histórias incompletas a catástrofe, que sucedeu em tempo que o meu amigo se retirara da sociedade, onde deixara a víscera dos afectos.

No volume denominado CORAÇÃO encontro algumas poesias, que não traslado, por desmerecerem publicidade, sobre serem imprestáveis ao

${ }^{25}$ ASSIS, cit., p. 873. 
contexto da obra. ${ }^{26}$

Como podemos notar, nos dois casos cadernos herdados pelo editor e, em especial no caso do Memorial e do livro de Camilo, a necessidade de o editor - mesmo a contragosto - reorganizar o material recebido para que ele possa ser publicado. Se o editor Machado, discretamente, apenas indicará que cortou trechos, Camilo, ou melhor, o personagem que ele constrói, a todo momento aparecerá na narrativa de seu amigo, complementando ou cortando trechos, e avisando, em muitos casos, a seu leitor a decisão editorial que está tomando. Apesar destas diferenças - que fazem o livro de Camilo, e não o de Machado, simular de forma pertinente o destino dos escritores nas mãos de seus editores -, são inegáveis as proximidades. Estamos diante do mesmo tipo de encenação que cria um segundo narrador que reorganiza os escritos de um outro, e muito longe da pretensa e pretendida objetividade de um narrador realista.

Comecei este texto afirmando que Balzac não pode ser tomado como um modelo de Camilo. Depois, mostrei como, sem nunca ser referido como fonte pelo autor de Anátema, podemos ver em certas posturas do autor de $O$ Judeu a metamorfose de alguns procedimentos de Alexandre Dumas. Por fim, tentei mostrar que alguns desdobramentos dessas posturas camilianas podem, novamente transmutados, ser encontrados na narrativa machadiana. Paulo Franchetti sugeriu que Camilo poderia ser considerado, estilisticamente, como próximo de Garrett, Sterne ou De Maistre, membro assim de uma família espiritual a que também pertence "com alguns degraus de parentesco que ainda cumpre determinar, entre outros, o nosso Machado de Assis". ${ }^{27}$

Pelo que aqui dissemos penso que seria possível pensar numa outra família que, partindo de Dumas, passaria por Camilo para, por fim, desembocar em Machado. Se, como apontou Juracy Assmann Saraiva, nos textos em que explicitamente cita Alexandre Dumas, é possível notar que o autor brasileiro "enaltece o escritor francês, mas também demonstra o [seu] distanciamento [...] em relação à obra dele, visto que o respeito não se traduz em filiação", talvez, através do aproveitamento e recriação de certas posturas narrativas presentes em Camilo, possa ser encontrado na obra machadiana, mesmo que profundamente transmutado, algo da voz do popular autor de $O$ conde de Monte Cristo.

${ }^{26}$ CASTELO BRANCO, cit., v. III, p. 731-733.

${ }^{27}$ FRANCHETTI, A novela camiliana. Acesso em: 11 mar. 2015. 


\section{Referências}

ASSIS, Machado de. Obra completa. Rio de Janeiro: Aguilar, 1959, v. 1.

BRAGA, Teófilo. As modernas ideias da literatura portuguesa. Porto: Chardron, 1892. CABRAL, Alexandre. Dicionário de Camilo Castelo Branco. Lisboa: Caminho, 2003. CASTELO BRANCO, Camilo. Obras completas. Porto: Lello \& Irmão, 1984, v. III; 1986, v. V; 1988, v. VIII.

CASTRO, Aníbal Pinto de. Contribuição para o estudo da influência de Balzac em Portugal e no Brasil. Coimbra: s.n., 1960.

DUMAS, Alexandre. Gabriel Lambert. Paris: Le Livre de Poche, 2009.

FRANCHETTI, Paulo. A novela camiliana. Disponível em: http://www.unicamp.br/iel/memoria/Ensaios/camiliana.htm. Acesso em: 11 mar. 2015.

Machado e Camilo. Disponível em: http://www.abralic.org.br/download/anaiseventos/cong2011/AnaisOnline/resumos /TC0622-1.pdf. Acesso em: 11 mar. 2015.

OLIVEIRA, Paulo Motta. Camilo Castelo Branco: de personas e emplastos. Tempo Brasileiro, v. 170. Rio de Janeiro, p. 57-70, 2007.

PASCOAES, Teixeira de. O penitente. Lisboa: Assírio \& Alvim, 1985.

PIMENTEL, Alberto. O romance do romancista. Lisboa: F. Pastor, 1890.

REIS, Carlos; PIRES, Maria da Natividade. História crítica da literatura portuguesa. 2. ed. Lisboa: Verbo, 1999.

RODRIGUES, A. A. Gonçalves. A tradução em Portugal. Lisboa: ISLA, 1992, 2. v. 1835/1850; 1993, 3. v. - 1851/1870.

SARAIVA, Juracy Assmann. Machado de Assis e o diálogo com Alexandre Dumas. In: SENNA, Marta de; GUIMARÃES, Hélio de Seixas (Orgs.). Machado de Assis e o outro: diálogos possíveis. Rio de Janeiro: Móbile, 2012.

SCHWARZ, Roberto. Um mestre na periferia do capitalismo: Machado de Assis. São Paulo: Duas Cidades, 1990.

SENNA, Marta de. O silêncio do bruxo: Machado de Assis e Camilo Castelo Branco. In: SENNA, Marta de; GUIMARÃES, Hélio de Seixas (Orgs.). Machado de Assis e o outro: diálogos possíveis. Rio de Janeiro: Móbile, 2012, p. 123-138. 
PAULO MOTTA OLIVEIRA é professor associado da Universidade de São Paulo. Entre seus trabalhos mais recentes estão: a organização do livro Travessias: D. João VI e o mundo lusófono (Ateliê, 2013) e a publicação dos artigos "De construções e apagamentos. Camilo e Ana", em: Representações do feminino em Camilo Castelo Branco (V. N. de Famalicão: Casa de Camilo - Centro de Estudos, 2014, v. 1, p. 229-249), e "The History of a Pseudo-Dumas Novel: The Hand of the Dead", em: Books and Periodicals in Brazil 1768-1930 (Londres: Legenda, 2014, v. 1, p. 118132). E-mail: pmotta@usp.br.

Recebido: 14.03.2015

Aprovado: 29.04.2015 